\title{
Market conditions, default risk and credit spreads
}

\author{
Dragon Yongjun Tang ${ }^{a}$, Hong Yan ${ }^{b, *}$ \\ ${ }^{a}$ School of Economics and Finance, University of Hong Kong, Hong Kong, China \\ ${ }^{b}$ Moore School of Business, University of South Carolina, Columbia, SC 29208, USA
}

This version: May 19, 2009

\begin{abstract}
This study empirically examines the impact of the interaction between market and default risk on corporate credit spreads. Using credit default swap (CDS) spreads, we find that average credit spreads decrease in GDP growth rate, but increase in GDP growth volatility and jump risk in the equity market. At the market level, investor sentiment is the most important determinant of credit spreads. At the firm level, credit spreads generally rise with cash flow volatility and beta, with the effect of cash flow beta varying with market conditions. We identify implied volatility as the most significant determinant of default risk among firmlevel characteristics. Overall, a major portion of individual credit spreads is accounted for by firm-level determinants of default risk, while macroeconomic variables are directly responsible for a lesser portion.

JEL Classification: G12; G13; E43; E44

Keywords: Credit risk; Credit default swaps; Credit spreads; Market conditions
\end{abstract}

* Corresponding author. Tel.: +1 8037774905.

Email addresses: yjtang@hku.hk (Tang), yanh@moore.sc.edu (Yan). 


\section{Introduction}

Credit risk and market risk are inherently linked. It has been documented that default probabilities and recovery rates vary through business cycles. ${ }^{1}$ It is also well known that interest rates and corporate bond yield spreads fluctuate over business cycles, as aggregate and firm-level outputs critically depend on the state of the economy. For instance, Fama and French (1989) find that bond yields rise when economic conditions are weak. However, these empirical findings have not been fully understood in a structural framework. In fact, traditional structural models based on the seminal Merton (1974) model have generally ignored the interaction between market risk and credit risk. Consequently, they have failed to match the levels of observed credits spreads ("the credit spread puzzle").

This paper examines the intrinsic link between market risk and credit risk inspired by recently developed structural models that directly explore the impact of market risk on credit spreads. $^{2}$ Specifically, we use individual firms' credit default swap (CDS) spreads to investigate new empirical implications from these structural models. For instance, in addition to the previously documented negative correlation between GDP growth rate and credit spreads, we show that credit spreads also increase in growth volatility as implied by these models. We further demonstrate that credit spreads decrease with a sentiment measure based on the Conference Board Consumer Confidence Index. Because consumer/investor sentiment is usually negatively correlated with the market-wide risk aversion and uncertainty about future eco-

\footnotetext{
${ }^{1}$ See, e.g., Acharya, Bharath, and Srinivasan (2007), Bonfim (2009), Bruche and González-Aguado (2009), Carling, Jacobson, Lindé, and Roszbach (2007), Duffie, Saita, and Wang (2007), and Pesaran, Schuermann, Treutler, and Weiner (2006).

${ }^{2}$ These models include Bhamra, Kuehn and Strebulaev (2007), Chen (2007), Chen, Collin-Dufresne and Goldstein (2007), David (2007), Hackbarth, Miao, and Morellec (2006), and Tang and Yan (2006).
} 
nomic growth, this result is consistent with the notion that credit spreads depend on investors' risk attitude and uncertainty about future economic prospects, as predicted by the models.

A number of existing empirical studies use yield spreads of corporate bond indices or average yield spreads within a particular rating class to characterize the dynamics of credit spreads (see, e.g., Huang and Huang, 2003). This approach may obscure the importance of firm heterogeneity and lead to underestimation of expected losses, as pointed out in Hanson, Pesaran and Schuermann (2008). With aggregate credit spreads, macro variables tend to explain a big portion of their variations over time. However, when we re-examine these relations in a panel regression, we find that firm characteristics traditionally determining default risk account for the bulk of the explanatory power, while a monthly time dummy that captures the time series variation in credit spreads accounts for just about $6 \%$ of the overall variation. Much of that explanatory power stems from the macro variables implied by the structural models, such as the sentiment indicator.

Recent models also provide additional cross-sectional predictions. We confirm that, across firms, credit spreads decrease with firm-specific growth rate of cash flows and increase with cash flow volatility, as predicted. More interestingly, we detect an important and time-varying role of cash flow beta, which measures the covariation of the firm-level cash flow with the aggregate output. In particular, the evidence suggests that during economic expansions, a high cash flow beta helps reduce credit spreads, while during economic recessions, a high cashflow beta may increase credit spreads. This pattern highlights the effect of the interaction of market risk and credit risk on the dynamics of credit spreads. 
Jarrow and Turnbull (2000) suggest that incorporating macroeconomic variables may improve a reduced-form model of credit spreads. Duffie, Saita and Wang (2007) use macroeconomic variables, such as industrial production growth, to help better predict corporate defaults. Our study represents an effort in a systematic investigation of the impact of market conditions on firm-level credit spreads in the structural framework provided by the recent theoretical models mentioned above. It also bridges the two strands of literature on credit risk that tend to focus separately on the macro and micro determinants and hence allows us to assess the relative explanatory power of macro and micro variables for firm-level credit spreads and examine the interaction between market conditions and firm characteristics.

The rest of this paper is organized as follows. Section 2 discusses the empirical implications of the recently developed models that incorporate market conditions into defaultable bond pricing. Section 3 introduces the CDS data used for the empirical analysis. Sections 4 and 5 present results of the time-series and cross-sectional patterns of credit spreads based on the model implications, respectively. Section 6 concludes.

\section{Empirical implications of recent theories}

The recent literature has seen a number of theoretical papers attempting to understand the link between credit spreads and macroeconomic risk. For example, Tang and Yan (2006) investigate the dynamics of firm-level credit spreads by highlighting the role of a firm's cash flow beta that measures its exposure to macroeconomic risk. They show that incorporating a macroeconomic influence on a firm's cash flow process helps improve significantly the fit of default probabilities and credit spreads. Other papers introduce habit-formation or 
recursive preference structures in order to illustrate the connection between the equity risk premium puzzle and the credit spread puzzle (Bhamra, Kuehn and Strebulaev (2007) and Chen, Collin-Dufresne and Goldstein (2007)), or reconcile the observed high credit spreads with low corporate leverage ratios (Chen, 2007). Moreover, Chen (2007) and David (2007) consider the impact of inflation and allow for regime-switching in the growth rate of aggregate consumption or production to capture the uncertainty in the business cycle. ${ }^{3}$ These models are calibrated to aggregate historical data and demonstrate a good fit with credit spreads on average.

Analysis in these papers manifests the significant impact of macroeconomic conditions on credit spreads, with major predictions consistent across all models. First, credit spreads are counter-cyclical, widening during recessions and narrowing during expansions. This result is related to the observed negative correlation between interest rates and credit spreads, as discussed in Longstaff and Schwartz (1995), due to an inherently close relation between the economic growth rate and the risk-free rate. While the counter-cyclical nature of credit spreads has been documented before, the intuition for this result is much more clear in these structural models: the growth rate of a firm's cash flow process is generally positively related to the economic growth rate. All else being equal, an increase in the economic growth rate, such as the GDP growth rate, will increase the firm-level growth rate and hence decrease the default probability and the credit spread.

\footnotetext{
${ }^{3}$ The regime-switching mechanism, also considered in Hackbarth, Miao, and Morellec (2006) and Bhamra, Kuehn and Strebulaev (2007), introduces a jump component in the pricing kernel and through its correlation with the flow-level cash flow prices a jump component at the firm level as well. This provides an economic backdrop to a structural model proposed by Leland (2006), who shows that with the addition of a jump component and liquidity costs, traditional structural models can be made to match both default probabilities and credit spreads.
} 
Second, theoretical analysis indicates that credit spreads increase with the volatility of the economic growth rate. A firm is more likely to experience cash flow shortfalls in a more volatile economic environment, and hence more likely to default. Therefore, this represents the effect of intertemporal economic risk, as the volatility of the economic growth rate tends to be higher in recessions than expansions. Hence, this implication distinguishes the risk effect from the growth effect discussed above.

Third, credit spreads also widen when investors are more risk averse. It has been argued that investors become more risk averse during economic downturns, and this effect has been linked to the "flight to quality" phenomenon. Even though some of the papers we discussed above do not explicitly model the endogenous change of investors' preferences, comparative static analysis provides a gauge of the sensitivity of credit spreads to changes in preferences. One possible proxy for investors' preferences is the measure of their sentiments. We will discuss further the use of sentiment measures to proxy for investors' attitude towards risk in our empirical examination.

The firm-level analysis also yields cross-sectional implications for credit spread dynamics and for the effect of the interaction between macroeconomic conditions and industry or firm-level characteristics. First, it indicates that credit spreads should decrease with the current firm-specific growth rate and increase with the volatility of cash flows. Secondly, the correlation between the firm-level cash flow and the aggregate output introduces an effect of cash flow beta. Credit spreads may increase with cash flow beta during an economic downturn while decrease with cash flow beta during an economic expansion. This highlights the 
impact of the interaction between market risk and credit risk on credit spreads due to firm heterogeneity.

In the remainder of this paper, we empirically examine these implications with the credit default swap (CDS) data, which we describe in the next section.

\section{Data and sample description}

Several data issues make empirical analysis of credit risk difficult. Corporate bond yields are known to contain substantial liquidity and tax premia due to illiquidty of the corporate bond market and different tax treatments between corporate bonds and Treasury bonds. Many corporate bonds also have embedded options, further complicating the measurement of credit spreads based on corporate bond yields. To make the matter worse, there is a debate about an adequate reference for the risk-free rate in order to obtain yield spreads.

The rapidly growing credit derivatives market provides a relief for the data problem. Without concerns of a reference risk-free rate and embedded optionality and with improved liquidity in the credit default swap (CDS) market, CDS spreads have become a preferred proxy for credit spreads. Duffie (1999) shows that under certain conditions, CDS spreads indeed equal credit spreads. Ericsson, Jocobs, and Oviedo (2007) and Tang and Yan (2007), among others, show that a large portion of CDS spreads can be directly attributed to credit risk.

Our CDS data are from two major CDS brokers: CreditTrade and GFI. Both data sources were previously used in the literature (e.g., GFI data in Hull, Predescu, and White (2004), 
and CreditTrade data in Blanco, Brennan, and Marshall (2005)). It is a rare instance to combine these two data sources. Our CreditTrade dataset spans from June 1997 to March 2006, and our GFI dataset covers the period between January 2002 and November $2006 .{ }^{4}$ In this study, we use CDS prices for non-sovereign U.S. corporate bond issuers denominated in U.S. dollars, with the reference issue ranked senior. The CDS contracts in our sample have maturities between 4.5 and 5.5 years. Monthly data are obtained by averaging transactions within the month. In our dataset, there are 26548 issuer-month CDS spread observations with an average CDS spread of 110.5 basis points.

Average CDS spreads are plotted in Figure 1. There is a significant time-series variation in average CDS spreads. CDS spreads peaked in the second half of 2002 due to the turbulence in the credit market. They subsequently declined, possibly due to (1) improved macroeconomic conditions which tend to reduce the aggregate credit risk; (2) increasing dominance of high quality issuers in the market; or (3) increased competition in the market that has improved the efficiency in the prices of CDS contracts.

In addition to CDS spreads, we also conduct some analysis with default probabilities using Moody's KMV's Expected Default Frequency (EDF). This measure is widely used in the industry. Its advantage comes from the frequent updating of credit situations because the indicator is based on the stock price of a reference firm. The time series of five-year market average EDF is plotted in Figure 1. It shows that EDFs and CDS spreads tend to move together, although there are periods when these two measures diverge (such as in 2001 and

\footnotetext{
${ }^{4}$ According to Risk magazine's inter-dealer rankings, CreditTrade was the number one CDS broker before 2004, and GFI has been the top credit derivatives broker in the last several years.
} 
2004).

Our sample selection is therefore limited to the firms with outstanding CDS contracts during the time period between June 1997 and November 2006. There are additional requirements pertaining to the number of observations needed in our analysis. These requirements will be discussed in the following two sections as they become relevant, together with descriptions of additional data of macroeconomic variables and firm-level characteristics.

\section{Macroeconomic conditions and credit spreads}

In this section, we empirically test several predictions from the structural credit risk models conditioned on macroeconomic variables. Our analysis employs the CDS data for credit spreads and Moody's KMV EDF data for the default probability measure. Hence, compared to existing empirical studies, our examination has two distinct advantages: high quality firm-level data of credit spreads and default risk, and a theory-motivated hypothesis.

\subsection{Hypothesis and variable construction}

The first implication of the theory is that default probability and credit spread decrease with the economic growth rate. The most intuitive proxy for economic growth is the real GDP growth rate. We obtain the real GDP data from the Federal Reserve Economic Database (FRED). ${ }^{5}$ GDP numbers are only available at the quarterly frequency. We interpolate quarterly GDP numbers to obtain monthly growth rates. For robustness check, we also report the results using the monthly industrial production growth rate, also from FRED, as a proxy for

\footnotetext{
${ }^{5}$ http://research.stlouisfed.org/fred2/
} 
economic growth.

The second implication of the theory is that default probability and credit spread increase with volatility of the economic growth rate. Estimating economic growth volatility, however, is a daunting task because economic growth rates are usually reported at a low frequency. To mitigate the problem with the lack of high-frequency macroeconomic data for a contemporaneous estimate of volatility, we follow McConnell and Perez Quiros (2000) and Stock and Watson (2002) and use the unexpected GDP growth rate to proxy for growth volatility by estimating the following $\mathrm{AR}(1)$ model:

$$
\Delta \mu_{t}=\omega+\phi \Delta \mu_{t-1}+\epsilon_{t}
$$

where $\Delta \mu_{t}$ is the monthly growth rate, $\phi$ measures the persistence of the growth rate. McConnell and Perez-Quiros (2000) show that $\sqrt{\pi / 2}\left|\epsilon_{t}\right|$ is an unbiased estimate of the true volatility. Hence, we use $\left|\epsilon_{t}\right|$ to proxy for growth volatility. ${ }^{6}$ We also apply this procedure to the growth rate of industrial production.

When investors are more risk averse, they require a higher risk premium for holding risky assets. Hence changing risk aversion will change the market risk premium and affect credit spreads as well. Unfortunately, we do not directly observe the level of investor risk aversion and its variation through time. A typical approach to estimate risk aversion is to extract

\footnotetext{
${ }^{6}$ We acknowledge a potential problem of measurement error with this proxy, especially with regime switching in GDP growth as shown by Stock and Watson (2005). However, this concern may be mitigated because the known structural break seems to have occurred in the mid-1980's, outside our sample period. We thank an anonymous referee for pointing out this measurement issue. For robustness check, we have also used monthly average implied volatility of the at-the-money S\&P 500 index options from OptionMetrics to proxy for the volatility of economic growth rate and obtain similar results.
} 
risk premium using option prices (see, e.g., Bliss and Panigirtzoglou (2004)). This approach generates one risk aversion estimate for each option and then a certain type of aggregation is needed to obtain an estimate for the market risk aversion. Instead of this elaborate process of estimating the market risk aversion, which is inherently model-dependent, we opt to using a measure of investor sentiment as a simple proxy. ${ }^{7}$ Therefore, we will investigate whether credit spread decreases with investor sentiment. Among several available measures of investor sentiment, only Conference Board Consumer Confidence Index and University of Michigan Consumer Sentiment are updated monthly. ${ }^{8}$ We report results using the monthly Conference Board Consumer Confidence Index as our sentiment measure, since similar results are obtained using the Michigan Consumer Confidence Index.

Leland (2006) argues that a jump component in a firm's asset process is critical to matching observed default probabilities with theoretical ones. The implication is that default probability and credit spread increase with jump risk. Empirically, we measure jump risk using the slope of implied volatility over strike prices (the "smile") for S\&P 500 index options, following Cremers, Driessen and Maenhout (2007).

Putting these implications together, the hypothesis we will test regarding the effect of the market risk on credit spreads can be summarized as the following:

\footnotetext{
${ }^{7}$ We recognize the important distinction between investor sentiment and risk aversion. Sentiment reflects investors' belief about future market movement. Risk aversion measures investors' taste for risky assets over risk-free assets. Nevertheless, these two measures are highly correlated. When investor sentiment is low, investors may save more in preparation for upcoming bad times, and hence raise the risk premium. Similar behavior may be observed in a market with highly risk averse investors.

${ }^{8}$ Other sentiment proxies include Barron's weekly investor confidence index, Investor Intelligence Index, State Street Investor Confidence Index, Hulbert Nasdaq Newsletter Sentiment Index, etc. Baker and Wurgler (2006) construct a sentiment measure, but it is only available on an annual basis. Qiu and Welch (2004) show that survey-based sentiment measures are superior to other constructed measures.
} 
Hypothesis 1 Default probability and credit spread are lower if the GDP growth rate is higher, if the growth volatility is lower, if the sentiment is stronger, and if the implied volatility smile of SEP 500 index options is flatter.

Figure 2 plots the time series of those macroeconomic variables, along with the market average CDS spreads. It illustrates that credit spreads are negatively correlated with investor sentiment but positively correlated with growth volatility. Table 1 provides the descriptive statistics of those macroeconomic variables. It shows that correlations among those series are rather low, thus mitigating the concern of multi-collinearity in multivariate regressions.

\subsection{Methodology}

Traditionally, empirical studies on the relations between credit spreads and macroeconomic variables use aggregated bond yield spreads because of data limitation. Our unique dataset allows us to employ various versions of regression analysis in order to evaluate the joint effects of macroeconomic variables and firm characteristics.

First, consistent with the traditional approach, we aggregate the CDS data to obtain a time series of market average CDS spreads and regress this series of average spreads on those four economic variables (the market average approach). This approach assumes that firm characteristics affecting credit spreads are not correlated with macroeconomic variables and the level of average credit spreads is solely determined by macroeconomic conditions.

Admittedly, this assumption is rather strong. For instance, Korajczyk and Levy (2003) show that firm leverage is strongly influenced by macroeconomic conditions. In order to 
relax this assumption, in the firm-by-firm approach, we regress firm-level CDS spreads on macroeconomic variables. We keep firms with at least 16 monthly observations and obtain 176 such time series regressions. We then calculate the cross-sectional means and standard errors of these coefficient estimates. The standard errors are adjusted by the number of firms in the cross-section. This approach, used by Collin-Dufresne, Goldstein, and Martin (2001), implicitly assumes that firms are independent in order to justify the standard errors.

In addition, we adopt a two-stage approach and denote it as the residuals approach. In the first stage, we regress CDS spreads on cross-sectional fundamental determinants of credit spreads with issuer fixed effects and monthly dummies. The coefficients for monthly dummies can be attributed to the time-series effect unaccounted for by cross-sectional variables. In the second stage, we regress the coefficient estimates for monthly dummies on macroeconomic variables.

Finally, we perform a panel regression analysis to assess the relative explanatory power of macroeconomic conditions and firm-level characteristics for credit spreads.

\subsection{Empirical analysis}

We start our analysis using the first three regression methodologies. We regress CDS spreads on the four macroeconomic variables and report the results in Table 2. Overall, macroeconomic conditions have a significant impact on credit spreads. Hypothesis 1 is strongly supported in all three approaches, with some variations in parameter estimates and their respective statistical significance across specifications. 
During our sample period, the GDP growth rate is a significant determinant of average credit spreads. As implied by Panel A of Table 2, on average, a one-percent increase in the GDP growth rate lowers credit spreads by 6-7 basis points. If we take the difference in GDP growth rates between expansions and recessions to be $7 \%$, then the credit spread difference across business cycles is in the neighborhood of $42-49$ basis points. We also find that growth volatility is positively related to credit spreads. A one-percent increase in growth volatility raises credit spreads by 2-7 basis points. In our sample, growth volatility can differ by about $3.5 \%$ across time, generating a change in credit spreads around $7-25$ basis points. $^{9}$

Investor sentiment is significantly and negatively associated with credit spreads. It has the highest $t$ value among the four macroeconomic variables in all three specifications. A one-standard deviation move in investor sentiment is associated with CDS spread change of about 25 basis points. Therefore, the effect of investor sentiment on credit spreads is also economically significant.

The effect of jump risk on credit spreads is positive but the significance level varies across specifications. In the Average and Residuals time-series regressions, a one-standard-deviation change in the jump risk affects average CDS spreads by about 4.6 basis points, at the $15 \%$ significance level. However, firm-level regressions show a highly significant jump risk effect, both statistically and economically. This result is actually sensible, because both Average and Residuals regressions are equivalent to examining the time-series properties of credit spreads of portfolios, thus ignoring the heterogeneity across firms pointed out in Hanson, Pesaran

\footnotetext{
${ }^{9}$ We find that the implied volatility of S\&P index options has a much stronger effect on credit spreads. However, because the implied volatility may reflect other influences in addition to growth volatility, we report here only the results on the growth volatility and will discuss the role of implied volatility later.
} 
and Schuermann (2008). The firm-level regressions take into account firm heterogeneity and demonstrate the importance of the systematic jump risk at the individual firm level. ${ }^{10}$ This is also consistent with the argument of Leland (2006) that a jump component is crucial for fitting credit spreads with structural models.

The differences in $R^{2}$ s across the three specifications are worth noting. First, about $57 \%$ of the variation in market average CDS spreads is accounted for by the four macroeconomic variables. The $R^{2}$ in the Residuals regression, which is similar to the market average regression in that it involves a times series regression of a cross-sectionally aggregated variable (time dummy), is consistent with this conjecture. In untabulated tests, we find that the time-series regression $R^{2}$ improves to $71 \%$ after we include other macroeconomic variables such as risk-free rate, term spread, AAA-BAA spread, etc. Secondly, the average $R^{2}$ of the firm-by-firm regressions is only $32 \%$, indicating that omitted firm heterogeneity could play a significant role in firm-level analysis, consistent with the argument in Hanson, Pesaran and Schuermann (2008).

As mentioned before, our monthly time series of the GDP growth rate is obtained through the interpolation of the quarterly data. We do, however, arrive at qualitatively similar results using quarterly data directly, albeit with fewer observations and hence reduced power. For a robustness check, we use the monthly observable industrial production (IP) instead of GDP in an analysis reported in Panel B of Table 2. The coefficient on the IP growth rate is significantly negative, consistent with that for the GDP growth rate. However, IP growth volatility is

\footnotetext{
${ }^{10}$ We find that distributions of firm-level regression coefficients are uni-modal, suggesting that credit risk induced by firm heterogeneity is to some extent diversifiable in portfolios.
} 
insignificant with an opposite sign compared to that for GDP growth volatility. Overall, the effect of IP growth on credit spreads appears to be weaker than that of GDP growth, and the $R^{2}$ s are generally lower in the IP analysis than in the GDP analysis. Furthermore, in an untabulated analysis, we find that the IP growth rate becomes insignificant after we include the GDP growth rate. This may indicate that GDP growth as a measure of the growth rate of the aggregate economic output, in which industrial production has a shrinking portion in recent years, may be a better state variable.

To alleviate concerns over the relatively short time series of the CDS data, we reexamine our analysis in Table 3 with Moody's Baa-Aaa spreads. This proxy of the aggregated market credit spreads is available over a much longer time span. We use data from 1976 until 2007 so that all independent variables, except for the jump proxy, are available and report the results of time-series analysis, which is comparable to the market average approach in Table 2. We do not include the jump proxy because the OptionMetrics data are only available after 1996. In column (1), the independent variables include the IP growth rate, which is used for its monthly availability, IP growth volatility, and the sentiment measure. All of them have statistically significant coefficients. Column (2) adds the short-term interest rate as an independent variable which improves the $R^{2}$ from $27.5 \%$ to $52 \%$. Column (3) sees the addition of other macro variables, such as long-term interest rate, term spread, stock market return and inflation rate, as explanatory variables and an improved $R^{2}$ of $58.4 \%$.

As an additional confirmation of the effect of macroeconomic conditions on default risk, we use Moody's KMV's EDF as a measure of default probability and regress EDFs on the 
macroeconomic variables. This exercise serves two important purposes. First, default probability is a purer measure of the risk of default, while credit spreads contain additional effects of recovery and liquidity. Secondly, the EDF measure has both one-year horizon and fiveyear horizon, and thus allows us to differentiate the impact of market conditions on the term structure of credit risk. This is not feasible at this time with the CDS data as prevailing CDS contracts in our dataset are of a five-year term. The time period of our analysis using the EDF measure is from January 1996 to October 2004, which overlaps a great deal with the time period in our analysis with CDS spreads.

The results of this analysis are reported in Table 4 with Panel A for 5-year EDFs and Panel B for 1-year EDFs. The overall results are consistent with the findings for credit spreads discussed above. We make two interesting observations. First, the statistical significance of the macroeconomic effect appears much stronger in firm-level regressions than in regressions on average or residual EDFs, a phenomenon that is more pronounced than in Table 2 with CDS spreads. This again highlights strongly the importance of firm heterogeneity in assessing credit risk. Secondly, the systematic jump risk is more significant for the short-term default risk than for the long-term default risk. This is consistent with the findings in Leland (2006) and Duffie and Lando (2001) that a jump component is instrumental for matching short-term default probabilities and credit spreads.

Traditional studies of determinants of credit spreads have focused separately on either macroeconomic variables or firm-level characteristics. Few have investigated the relative explanatory power of macro and micro variables for credit spreads. We address this issue in 
Table 5, where we first investigate the explanatory power of macro variables alone in the panel in Panel A. The first column contains only the monthly dummy as the independent variable, which should capture all the time-series variations attributed to macroeconomic conditions. It indicates that the aggregate macro effect accounts for $6.3 \%$ in the overall variation of CDS spreads. This is a far cry from the high $R^{2}$ observed in earlier studies of aggregated credit spreads.

In order to see how well the proposed macro variables we discussed before represent market conditions, we replace monthly dummies with our four macro variables in column (2) in Panel A. The resulting $R^{2}$ is $2.7 \%$ or about $43 \%$ of the total macro effect. We are mindful of the potential measurement problem with GDP growth volatility and proxy for growth volatility using the implied volatility of at-the-money S\&P 500 index options instead in column (3). We find that this implied volatility proxy has much more explanatory power than our measure of GDP growth volatility, as the $R^{2}$ increases from $2.7 \%$ to $4.1 \%$. This may be due to the fact that the implied volatility measure contains information beyond the market expectation of future growth volatility, such as aggregate default probability since equity is generally leveraged. Hence, the alternative measure of growth volatility helps increase explanatory power to $65 \%$ of the total macro effect. Moreover, including other six common measures of macroeconomic variables (short rate, long rate, term spread, credit spread, stock market return, and inflation) can eventually increase the $R^{2}$ to $5.1 \%$ or $81 \%$ of the total macroeconomic effect. Therefore, our four macro variables capture a reasonable amount of the total macro effect.

In Panel B, we compare the explanatory power of macroeconomic conditions relative to 
firm characteristics such as leverage, volatility and jump that are commonly used determinants of firm-level default probability. We find that firm characteristics explain much more of the overall CDS spread variations ( $R^{2}$ of $47.2 \%$ without monthly dummies in column (3) versus $53.7 \%$ with monthly dummies in column (4)). However, the macroeconomic effect is distinct from the effect of firm characteristics. Their explanatory power is largely complementary: the aggregate explanatory power of $53.7 \%$ is about the sum of the $R^{2}$ for monthly dummies, $6.1 \%$ in column (1), and the $R^{2}$ for firm characteristics, $47.2 \%$ in column (3). Note that, as shown in column (2), a strong explanatory variable is the firm-level implied volatility, as it captures the bulk of cross-sectional variations, consistent with Campbell and Taksler (2003). While still a large portion of the CDS spread variation is not explained, consistent with CollinDufresne, Goldstein, and Martin (2001), the macroeconomic effect accounts for about $11 \%$ of the explained portion of overall CDS variations.

The high explanatory power of macroeconomic variables for aggregated credit spreads and their relatively low explanatory power for firm-level credit spreads suggest that macroeconomic conditions impact credit spreads through multiple channels. One is a direct channel, through a common factor variation in the pricing kernel, as reflected in the effect of market volatility, growth rate and investor sentiment. Another is an indirect channel, through their covariation with firm-level default probabilities, as demonstrated in Table 4. Therefore, our analysis suggests that most of the impact of market conditions on credit spreads appears to go through the indirect channel. 


\section{Firm characteristics and credit spreads}

Our analysis thus far suggests the importance of firm heterogeneity. There have been many studies that document the role of firm-level characteristics, such as leverage ratio, profitability, and stock volatility, in determining firm-level default probabilities and credit spreads. Theoretically, Tang and Yan (2006) make additional predictions on the effect of firm's cash-flow characteristics on credit spreads and on the interaction between market conditions and credit risk. In this section, we empirically test these predictions.

\subsection{Hypotheses and cash flow variable construction}

The effect of cash flow variables on credit spreads has not been extensively examined in the empirical credit risk literature. We are aware of only a couple of studies, such as Minton and Schrand (1999) and Molina (2005), that analyze the effect of cash flow volatility on corporate bond yield spreads. When a firm's cash flow is more volatile, it is more likely that the firm will have a cash shortfall, which may lead to financial distress and even default. Therefore, we should expect that credit spread increases with cash flow volatility. Indeed, Minton and Schrand (1999) and Molina (2005) have presented evidence in support of this prediction. We re-evaluate this relation, along with other new predictions, using a different credit spread measure and a different econometric method.

We measure the quarterly operating cash flow (OCF) as operating income before depreciation (Compustat data item 21) adjusted for working capital accruals (Dechow, 1994). ${ }^{11}$

\footnotetext{
${ }^{11}$ Minton and Schrand (1999) argue that debtholders can only claim the firm value after investments. They adjust this operating cash flow number for investment expenditures that are expensed as part of operating income by adding back quarterly R\&D and advertising expenses. Our results are not qualitatively affected by
} 
Cash flow volatility is measured as the coefficient of variation in a firm's quarterly operating cash flows over the past six year period:

$$
\mathrm{CVCF}=100 \times \frac{\text { standard deviation of } \mathrm{OCF}}{\mid \text { mean of } \mathrm{OCF} \mid}
$$

A minimum of twelve quarterly observations is required to calculate CVCF. We use a sixyear rolling window to calculate $\mathrm{CVCF}$ in order to obtain a more accurate measure. Similar windows are used by Minton and Schrand (1999) and Molina (2005).

Some firms thrive even during economic downturns. Firms with higher firm-specific growth rates are more likely to avoid default, ceteris paribus. Therefore, we should expect that credit spread decreases with the firm specific growth rate. Accordingly, we run the following regression for each firm $i$ using data from the previous six years to obtain the firm-specific growth rate, $\alpha^{i}$, for each month:

$$
\xi_{t}^{i}=\alpha^{i}+\beta^{i} \mu_{t}+\epsilon_{t}^{i},
$$

where $\xi_{t}^{i}$ is firm $i$ 's total cash flow growth rate, $\mu_{t}$ is the GDP growth rate, $\beta^{i}$ is firm $i$ 's cash flow beta, and $\epsilon_{t}^{i}$ is random noise. Alternatively, we use $\alpha^{i}+\epsilon_{t}^{i}$ to proxy for the firm-specific growth rate and the results are similar with those using $\alpha^{i}$ alone.

Moreover, a higher systematic growth component should affect credit spreads. Cash flow beta $\left(\beta^{i}\right)$ in $(3)$ measures the systematic exposure of firm-level cash flows. Since economic expansions are much longer than recessions, we should expect that unconditionally, credit this adjustment. We do not make such an adjustment here because it would significantly reduce the number of available observations. 
spread decreases with cash flow beta across firms. Hence, we can summarize the discussion above into the following hypothesis:

HYPOTHESIS 2 In the cross section, credit spread increases with cash flow volatility, decreases with firm-specific growth rate and with cash flow beta.

There is also a conditional effect of cash flow beta $\left(\beta^{i}\right)$ on credit spreads that varies with macroeconomic conditions. Firms with a high beta are more likely to perform well in an up market. In a down market, however, high correlation with the market is not desirable. Campbell and Vuolteenaho (2004) distinguish cash flow beta from discount rate beta and argue that cash flow beta should have a higher price of risk. Here, we test the following hypothesis on the interaction between firm characteristics and macroeconomic conditions:

Hypothesis 3 Credit spread decreases with the firm-level cash flow beta during economic expansions, while increases with the firm-level cash flow beta during economic downturns.

In order to test this hypothesis, we need to identify different economic conditions. In our data sample period, there are only three quarters with negative GDP growth: 2001Q3 $(-1.41 \%$, annualized), 2001Q1 $(-0.49 \%), 2000 \mathrm{Q} 3(-0.46 \%)$. We regress credit spreads on cash flow betas, obtained from (3), separately for negative growth periods and for positive growth periods and examine whether the signs are different in different economic phases.

Cash flow estimates are summarized in Panel A of Table 6. The cross-sectional variations of all three variables are quite significant. Firm-level cash flows are very volatile, consistent 
with the accounting literature, with the sample average cash-flow volatility around $173 \% .{ }^{12}$ Cash flow growth is also very sensitive to the economic growth rate. The average of firm cash flow beta is 82.68 , although the distribution of cash flow betas appears to be quite skewed. Firms with higher firm specific growth rates have more volatile cash flows and lower cash flow betas, as illustrated in the correlation matrix.

\subsection{Methodology}

Our dataset is a pooled time-series and cross-section unbalanced panel. Extra care needs to be taken to analyze such a panel. Thompson (2006) and Petersen (2009) provides a detailed analysis on the performance of various approaches for this type of analysis. We follow their suggestion and conduct our regression analysis by adjusting for issuer clustering and controlling for the time effect with monthly dummies. Because of the use of time dummies, we do not include any other macroeconomic variables in our analysis. The specification we use in our regression analysis is then:

$$
C D S \text { Spread }_{i t}=\gamma_{0}+\gamma_{1} \times C V C F_{i t}+\gamma_{2} \times F S G_{i t}+\gamma_{3} C F \text { Beta }_{i t}+\text { Controls }+\epsilon_{i t}
$$

with issuer-clustered $t$-statistics for the coefficients, where $C V C F$ is the cash flow volatility, $F S G$ is the firm-specific growth rate, and CFBeta is the cash flow beta.

For firm-level control variables, we include leverage (measured as the book debt over the sum of book debt and market equity), asset volatility (proxied by the at-the-money option-

\footnotetext{
${ }^{12}$ Cash flows, unlike earnings, are hard to smooth by managers.
} 
implied volatility from OptionMetrics), and jump risk (proxied by the slope of the implied volatility curve from OptionMetrics), following the literature (see, e.g., Zhang, Zhou, and Zhu (2008)). Panel B of Table 6 provides summary statistics for the control variables. The average firm has leverage of $30 \%$, implied volatility of 0.33 and jump risk of $0.27 \%$.

\subsection{Empirical analysis}

Table 7 presents the panel regression results. The coefficient estimates on those monthly dummies are not shown to save space. Issuer clustering, cross correlation, and heteroskadasticity are adjusted to obtain robust $t$-statistics.

We find cash flow volatility to be a statistically significant explanatory variable for CDS spreads, consistent with Minton and Schrand (1999) and Molina (2005). However, its economic significance seems modest (column 1), as a one-standard-deviation move in cash flow volatility only changes credit spreads by about 9 basis points. The firm-specific growth rate is only marginally significant, at the $10 \%$ level. Note that the firm-specific growth rate embodies the firm-specific risk, so in a well-diversified market, its pricing impact should be diminished, even though the option nature of bonds may retain some of its effect. Our result is therefore consistent with the notion that systematic, not firm-specific, factors exert a stronger impact on bond pricing. This notion is further bolstered by the significant impact of cash flow beta on credit spreads. Overall, the results are consistent with the predictions in Hypothesis 2.

Although firm-level cash flow variables have stand-alone explanatory power, represented by $R^{2}$ of $6.2 \%$ in column 1 of Table 7 , their marginal explanatory power is negligible once time dummy and other firm characteristics such as leverage, implied volatility, and jump are 
included in the regression, as indicated by $R^{2} \mathrm{~s}$ in column 3 and in column 4 . In a related study, Das, Hanouna and Sarin (2009) show that accounting-based and market-based models have similar explanatory power for CDS spreads and argue that information from these two types of models may be complementary in pricing financial distress.

Hypothesis 3 is a novel prediction. It demonstrates the effect of the interaction between macroeconomic conditions and firm characteristics. To test this hypothesis, we run separate cross-sectional regressions for periods with negative and positive economic growth and report results in Table 8 . We find some supportive evidence for the hypothesis, which comes mainly from positive growth periods (Panel A) when high-beta firms have lower credit spreads, consistent with the unconditional result in Table 7 . We also find that firms with higher cash flower beta have higher credit spreads when the economy has a negative growth rate, although the coefficient estimate is not statistically significant due to the paucity of negative growth periods (three quarters) in our data span (Panel B). To test the sign difference of the coefficients across different economic states, we add an interaction term (cash flow beta with negative growth dummy) to the regression model. As reported in Panel $\mathrm{C}$, the interaction term is significant at the $10 \%$ level with a $t$-statistic of 1.84 . Therefore, the effect of cash flow beta on credit spreads is indeed different in economic expansions than in recessions. Moreover, we confirm that this pattern persists when we use the NBER classification of economic expansions and recessions (March - November 2001) during our sample period. The signs are different with a $t$-statistic of 2.63 .

In this part of our empirical investigation, we use regression estimates (firm-specific growth 
rate and cash flow beta) as independent variables. This could potentially introduce an error-invariable problem. Shanken (1992) shows that, in the presence of the error-in-variable problem, the two-pass Fama-MacBeth approach could result in biased coefficient estimates and incorrect standard errors. If estimation errors within the same cluster are highly correlated, however, our clustering adjustment in the panel data regression may alleviate this concern because the cluster-level correlation is controlled for. At this point, we are not aware of any formal procedure that handles the error-in-variable problem in panel regressions.

\section{Conclusion}

We empirically examine the effect of market conditions on credit spreads, motivated by the recent structural models that explicitly consider the joint effect of market risk and credit risk. Our study uses large scale firm-level CDS data that allow us to investigate the relative explanatory power of macroeconomic conditions and firm characteristics and the effect of their interactions. We show that the macroeconomic condition accounts for about $6 \%$ of the overall variation of credit spreads (11\% of the explained portion), and the model-based variables such as growth rate, growth volatility, investor sentiment, and jump risk, contribute much of the explanatory power. Firm-level determinants account for a bigger portion of the overall variation of credit spreads, highlighting the importance of firm heterogeneity for credit risk modeling and management.

We identify investor sentiment at the aggregate market level and implied volatility at the firm level as the most important credit spread determinants. Firm-specific cash flow characteristics such as growth rate, growth volatility, and beta also have stand-alone explanatory 
power. Moreover, we provide evidence on the importance of the interaction between market conditions and firm-specific characteristics. Specifically, during economic expansions, firms with high cash flow betas have lower credit spreads, ceteris paribus, than firms with low cash flow betas. This relation reverses during economic recessions.

This study illustrates one of the ways the interaction of market risk and credit risk can transpire in the credit market. The empirical findings provide support to a cash flow beta representation, which may facilitate further investigation of credit risk in a portfolio context and enable the development of better risk management tools for banks and corporations.

\section{Acknowledgements}

We are grateful to Til Schuermann (discussant and guest editor) and other participants of the Joint Conference of the Deutsche Bundesbank, the Basel Committee on Banking Supervision and the Journal of Banking and Finance on the Interaction of Market and Credit Risk for useful insights. Two anonymous referees provided detailed suggestions that have helped improve the paper. We thank Lorenzo Garlappi, Shisheng Qu, Sheridan Titman, Efstathios Tompaidis, Sergey Tsyplakov and participants of the McGill University/IFM² Second Risk Management Conference, 2008 NTU IEFA Conference, 2nd NUS Risk Management Conference, 2008 China International Conference in Finance, and 2008 Asian Finance Association Meeting, especially our discussants, Antje Berndt, Hsiou-wei Lin, Jing-zhi Huang, Jun Yang, and Bing-Huei Lin, for helpful comments. 


\section{References}

Acharya, V.V., Bharath, S.T., Srinivasan, A., 2007. Does industry-wide distress affect defaulted Firms? Evidence from creditor recoveries. Journal of Financial Economics 85, $787-821$.

Baker, M., Wurgler, J., 2006. Investor sentiment and the cross section of stock returns. Journal of Finance 61, 1645-1680.

Bhamra, H.S., Kuehn, L., Strebulaev, I.A., 2007. The levered equity risk premium and credit spreads: A unified framework. Working paper, UBC and Stanford.

Blanco, R., Brennan, S., Marsh, I.W., 2005. An empirical analysis of the dynamic relationship between investment grade bonds and credit default swaps. Journal of Finance 60, $2255-2281$.

Bliss, R.R., Panigirtzoglou, N., 2004. Option-implied risk aversion estimates. Journal of Finance 59, 407-446.

Bonfim, D., 2009. Credit risk drivers: Evaluating the contribution of firm level information and of macroeconomic dynamics. Journal of Banking and Finance 33, 281-299.

Bruche, M., González-Aguado, C., 2009. Recovery rates, default probabilities, and the credit cycle. Journal of Banking and Finance forthcoming.

Campbell, J.Y., Taksler, G.B., 2003. Equity volatility and corporate bond yields. Journal of Finance 58, 2321-2349.

Campbell, J.Y., Vuolteenaho, T., 2004. Bad beta, good beta. American Economic Review 94, 1249-1275.

Carling, K., Jacobson, T., Lindé, J., Roszbach, K., 2007. Corporate credit risk modeling and the macroeconomy. Journal of Banking and Finance 31, 845-868.

Chen, H., 2007. Macroeconomic conditions and the puzzles of credit spreads and capital structure. Working paper, MIT.

Chen, L., Collin-Dufresne, P., Goldstein, R.S., 2007. On the relation between the credit spread puzzle and the equity premium puzzle. Review of Financial Studies forthcoming.

Collin-Dufresne, P., Goldstein, R.S., Martin, J.S., 2001. The determinants of credit spread change. Journal of Finance 56, 2177-2207.

Cremers, M., Driessen, J., Maenhout, P., 2007. Explaining the level of credit spreads: Option-implied jump risk premia in a firm value model. Review of Financial Studies forthcoming. 
Das, S.R., Hanouna, P., Sarin, A., 2009. Accounting-based versus market-based crosssectional models of CDS spreads. Journal of Banking and Finance 33, 719-730.

David, A., 2007. Inflation uncertainty, asset valuations, and the credit spreads puzzle. Review of Financial Studies forthcoming.

Dechow, P., 1994. Accounting earnings and cash flows as measures of firm performance: The role of accounting accruals. Journal of Accounting and Economics 18, 3-42.

Duffie, D., 1999. Credit swap valuation. Financial Analysts Journal (January/February), 73-87.

Duffie, D., Lando, D., 2001. Term structures of credit spreads with incomplete accounting information. Econometrica 69, 633-664.

Duffie, D., Saita, L., Wang, K., 2007. Multi-period corporate default prediction with stochastic covariates. Journal of Financial Economics 83, 635-665.

Ericsson, J., Jacobs, K., Oviedo, R., 2007. The determinants of credit default swap premia. Journal of Financial and Quantitative Analysis forthcoming.

Fama, E.F., French, K.R., 1989. Business conditions and expected returns on stocks and bonds. Journal of Financial Economics 25, 23-49.

Hackbarth, D., Miao, J., Morellec, E., 2006. Capital structure, credit risk, and macroeconomic conditions. Journal of Financial Economics 82, 519-550.

Hanson, S.G., Pesaran, M.H., Schuermann, T., 2008. Firm heterogeneity and credit risk diversification. Journal of Empirical Finance 15, 583-612.

Huang, J., Huang, M., 2003. How much of credit spread is due to credit risk? Working paper, Penn State and Stanford University.

Hull, J., Predescu, M., White, A., 2004. The relationship between credit default swap spreads, bond yields, and credit rating announcements. Journal of Banking and Finance 28, 2789-2811.

Jarrow, R.A., Turnbull, S.M., 2000. The intersection of market and credit risk. Journal of Banking and Finance 24, 271-299.

Korajczyk, R.A., Levy, A., 2003. Capital structure choice: macroeconomic conditions and financial constraints. Journal of Financial Economics 68, 75-109.

Leland, H.E., 2006. Structural models in corporate finance. Princeton University Bendheim Lecture Series in Finance.

Longstaff, F.A., Schwartz, E.S., 1995. A simple approach to valuing risky fixed and floating rate debt. Journal of Finance 50, 789-819. 
McConnell, M.M., Perez-Quiros, G., 2000. Output fluctuations in the United States: What has changed since the early 1980s? American Economic Review 90, 1464-1476.

Merton, R.C., 1974. On the pricing of corporate debt: The risk structure of interest rates. Journal of Finance 29, 449-470.

Minton, B.A., Schrand, C., 1999. The impact of cash flow volatility on discretionary investment and the costs of debt and equity financing. Journal of Financial Economics 54, 423-460.

Molina, C.A., 2005. Are firms underleveraged? An examination of the effect of leverage on default probabilities. Journal of Finance 60, 1427-1459.

Pesaran, M.H., Schuermann T., Treutler, B.-J., Weiner, S.M., 2006. Macroeconomic dynamics and credit risk: A global perspective. Journal of Money, Credit, and Banking $38,1211-1262$.

Petersen, M.A., 2009. Estimating standard errors in finance panel data sets: Comparing approaches. Review of Financial Studies 22, 435-480.

Qiu, L., Welch, I., 2005. Investor sentiment measures. Working paper, Brown University.

Shanken, J., 1992. On the estimation of beta-pricing models. Review of Financial Studies $5,1-33$.

Stock, J.H., Watson, M.W., 2002. Has the business cycle changed and why? NBER Macroeconomics Annual 2002, 159-218.

Stock, J.H., Watson, M.W., 2005. Understanding changes in international business cycle dynamics. Journal of the European Economic Association 3, 968-1006.

Tang, D.Y., Yan, H., 2006. Macroeconomic conditions, firm characteristics, and credit spreads. Journal of Financial Services Research 29, 177-210.

Tang, D.Y., Yan, H., 2007. Liquidity and credit default swap spreads. Working paper, University of Hong Kong and University of South Carolina.

Thompson, S.B., 2006. Simple formulas for standard errors that cluster by both firm and time. Working paper, Harvard University.

Zhang, B.Y., Zhou, H., Zhu, H., 2008. Explaining credit default swap spreads with equity volatility and jump risks of individual firms. Review of Financial Studies forthcoming. 


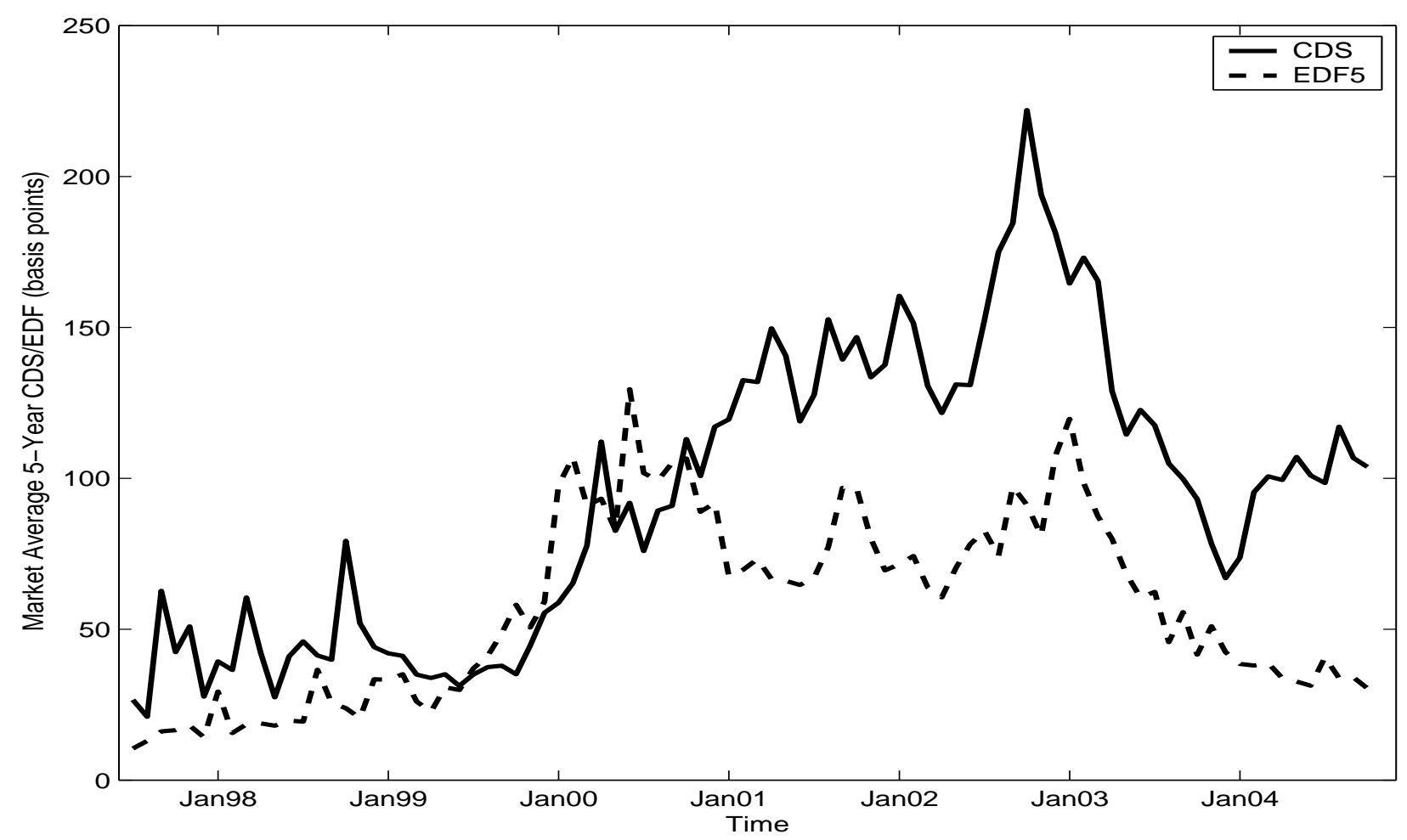

Figure 1. Market average 5-year CDS spreads and 5-year EDFs. 


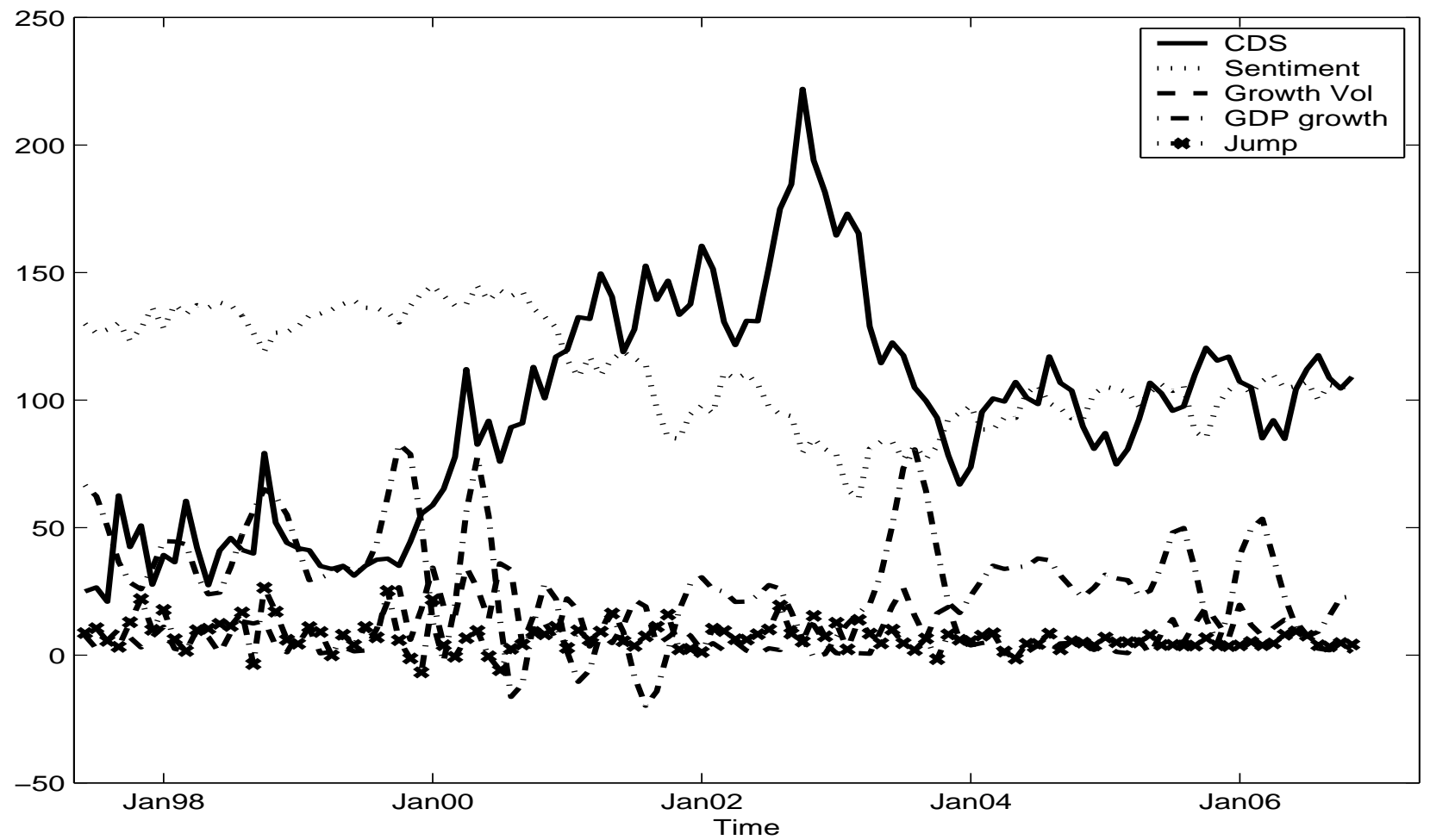

Figure 2. CDS and Macroeconomic Variables.

This figure plots the market monthly average 5-year CDS spreads and the monthly time series of four macroeconomic variables: real GDP growth rate, GDP growth volatility estimated as the unexpected growth rate, investor sentiment proxied by Conference Board Consumer Confidence Index, and jump risk proxied by S\&P 500 index option implied volatility slope. GDP growth and growth volatility are multiplied by 1000. Jump is multiplied by 10000 . 


\section{Table 1}

Descriptive statistics for macroeconomic variables

\begin{tabular}{lrrrrrrrrr}
\hline \hline & & & & & & & \multicolumn{3}{c}{ Correlation } \\
\cline { 7 - 10 } Variable & Obs & Mean & Std. & Min & Max & AR $(1)$ & $(1)$ & $(2)$ & $(3)$ \\
\hline GDP Growth (1) & 106 & $3.21 \%$ & $2.24 \%$ & $-1.98 \%$ & $8.28 \%$ & 0.85 & 1.00 & & \\
GDP Vol (2) & 106 & $0.97 \%$ & $0.84 \%$ & $0.04 \%$ & $3.60 \%$ & 0.27 & 0.10 & 1.00 & \\
Sentiment (3) & 106 & 113.06 & 21.15 & 61.42 & 144.71 & 0.89 & 0.15 & 0.26 & 1.00 \\
Jump $\left(\times 10^{4}\right)$ & 106 & 7.69 & 5.73 & -6.72 & 26.42 & 0.18 & -0.02 & -0.06 & 0.01 \\
\hline
\end{tabular}

Notes: This table presents descriptive statistics of the four monthly macroeconomic series: real GDP growth rate, GDP growth volatility estimated as the unexpected growth rate, investor sentiment proxied by Conference Board Consumer Confidence Index, and jump risk proxied by S\&P 500 index option implied volatility slope. GDP growth rate is interpolated from quarterly observations to a monthly series. The time period spans from July 1997 to November 2006. 
Table 2

Macroeconomic conditions and credit spreads

\begin{tabular}{|c|c|c|c|c|c|c|}
\hline & \multicolumn{2}{|c|}{ Average } & \multicolumn{2}{|c|}{ Firm-by-firm } & \multicolumn{2}{|c|}{ Residuals } \\
\hline & Coef & t-stat & Coef & t-stat & Coef & t-stat \\
\hline & \multicolumn{6}{|c|}{ Panel A: GDP as Macroeconomic Proxy } \\
\hline Intercept & 244.43 & 15.85 & 234.67 & 12.29 & 129.68 & 8.57 \\
\hline GDP Growth & -700.61 & -5.45 & -562.72 & -8.20 & -655.44 & -5.21 \\
\hline Growth Volatility & 555.62 & 1.97 & 158.65 & 1.81 & 701.52 & 2.14 \\
\hline Sentiment & -1.22 & -8.65 & -1.39 & -8.57 & -1.16 & -8.42 \\
\hline Jump $\left(\times 10^{4}\right)$ & 0.79 & 1.45 & 3.23 & 11.31 & 0.78 & 1.45 \\
\hline $\mathrm{N}$ & 95 & & 284 & & 94 & \\
\hline$R^{2}$ & 0.572 & & 0.321 & & 0.555 & \\
\hline
\end{tabular}

\begin{tabular}{|c|c|c|c|c|c|c|}
\hline \multirow[b]{2}{*}{ Intercept } & \multicolumn{6}{|c|}{ Panel B: Industrial Production (IP) as Macroeconomic Proxy } \\
\hline & 224.65 & 12.80 & 258.73 & 12.10 & 81.54 & 4.58 \\
\hline IP Growth & -130.41 & -2.48 & -100.84 & -6.01 & -135.71 & -2.53 \\
\hline Growth Volatility & -15.65 & -0.18 & -78.17 & -1.86 & -8.69 & -0.10 \\
\hline Sentiment & -1.14 & -7.68 & -1.58 & -9.19 & -1.06 & -7.07 \\
\hline Jump $\left(\times 10^{4}\right)$ & 1.02 & 1.66 & 2.08 & 3.55 & 0.87 & 1.40 \\
\hline$\overline{\mathrm{N}}$ & 95 & & 284 & & 94 & \\
\hline$R^{2}$ & 0.463 & & 0.242 & & 0.430 & \\
\hline
\end{tabular}

Notes: This table reports the regression results of credit spreads on macroeconomic variables. The dependent variable is the 5-year monthly average CDS spreads in basis points. The CDS sample includes US dollar denominated contracts for US corporations with reference issues being senior unsecured bonds for the time period spanning from January 1999 to November 2006. The independent variables for Panel A are the four monthly macroeconomic series: real GDP growth rate, GDP growth volatility estimated as the unexpected growth rate, investor sentiment proxied by Conference Board Consumer Confidence Index, and jump risk proxied by S\&P 500 index option implied volatility slope. In Panel B, GDP is replaced by Industrial Production. For the Average regression, market average CDS spread is the dependent variable. The firm-by-firm regression regresses firm CDS spreads on macroeconomic variables and then coefficients are averaged across all issuers. Standard errors were adjusted by the number of issuers. In the Residuals regression, firm CDS spreads are first regressed in a panel regression with monthly time dummies. The coefficient estimates for time dummies are then regressed on macro variables. First order autocorrelation is corrected for the Average and Residuals specifications. 
Table 3

Long time series with Baa-Aaa spreads

\begin{tabular}{|c|c|c|c|c|c|c|}
\hline & \multicolumn{2}{|c|}{$(1)$} & \multicolumn{2}{|c|}{$(2)$} & \multicolumn{2}{|c|}{$(3)$} \\
\hline & Coef & t-stat & Coef & t-stat & Coef & t-stat \\
\hline Intercept & 1.85 & 19.37 & 1.40 & 16.60 & 0.81 & 5.06 \\
\hline IP growth & -0.84 & -3.33 & -0.61 & -2.96 & -0.84 & -4.33 \\
\hline IP growth vol & 1.22 & 3.09 & 0.40 & 2.21 & 0.80 & 2.58 \\
\hline Sentiment & -0.01 & -9.44 & -0.01 & -10.56 & -0.01 & -5.07 \\
\hline Short rate & & & 0.07 & 13.71 & 0.04 & 1.24 \\
\hline Long rate & & & & & 0.07 & 2.65 \\
\hline Term spread & & & & & 0.06 & 1.09 \\
\hline Stock return & & & & & 0.82 & 1.93 \\
\hline Inflation & & & & & -1.61 & -1.95 \\
\hline $\mathrm{N}$ & 379 & & 379 & & 379 & \\
\hline Adj. $R^{2}$ & $27.5 \%$ & & $52.0 \%$ & & $58.4 \%$ & \\
\hline
\end{tabular}

Notes: This table demonstrates how much various macroeconomic variables explain Moody's Baa-Aaa spreads. The dependent variable is monthly Moody's Baa-Aaa spreads. The reported results are for the time period spanning from July 1976 to December 2007. The independent variables include three monthly macroeconomic series: real industrial production (IP) growth rate, IP growth volatility estimated as the unexpected growth rate, and investor sentiment proxied by Conference Board Consumer Confidence Index. Short rate is three-month Treasury bill yield. Long rate is ten-year government bond yield. Term spread is the yield difference between 10-year and 2-year Treasury bonds. Stock return is monthly $\mathrm{S} \& \mathrm{P}$ stock return. Inflation is year-over-year CPI percentage change. Robust $t$-statistics are reported. 
Table 4

Macroeconomic conditions and default probabilities

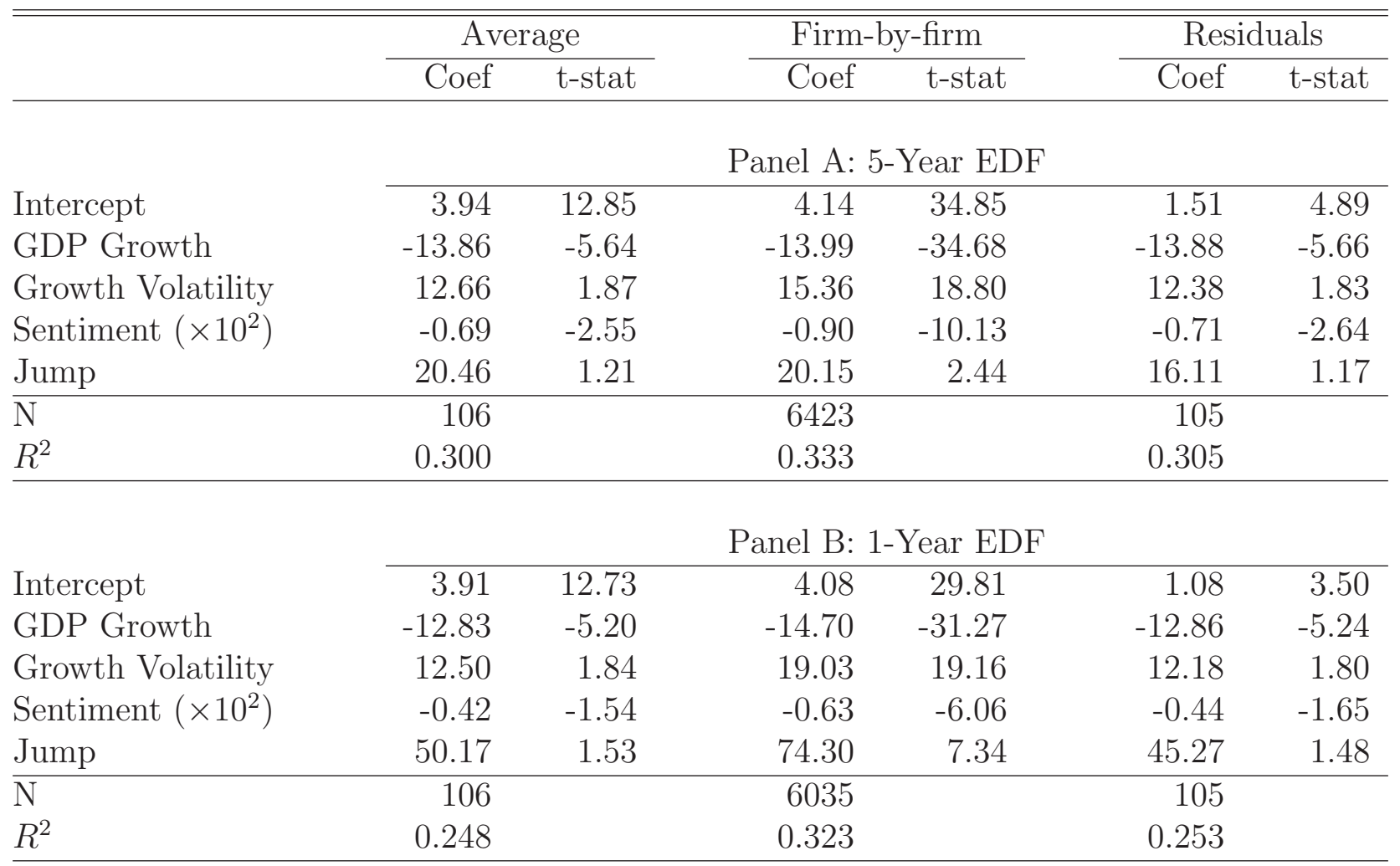

Notes: This table reports the regression results of default probabilities on macroeconomic variables. The dependent variables are the 5-year (Panel A) and 1-year (Panel B) monthly Expected Default Frequency (EDF) from Moody's KMV. The reported results are for the time period spanning from January 1996 to October 2004. The independent variables are the four macroeconomic variables measured at the monthly interval: real GDP growth rate, GDP growth volatility estimated as the unexpected growth rate, investor sentiment proxied by Conference Board Consumer Confidence Index, and jump risk proxied by S\&P 500 index options' implied volatility slope. For the Average regression, market average EDF is the dependent variable. The firm-by-firm regression regresses firm EDFs on macroeconomic variables and then coefficients are averaged across all issuers. Standard errors were adjusted by the number of issuers. In the Residuals regression, firm EDFs are first regressed in a panel regression with monthly time dummies. The coefficient estimates for time dummies are then regressed on macro variables. First order autocorrelation is corrected for the Average and Residuals specifications. 
Table 5

Relative explanatory powers

\begin{tabular}{|c|c|c|c|c|c|c|c|c|}
\hline & \multicolumn{2}{|c|}{$(1)$} & \multicolumn{2}{|c|}{$(2)$} & \multicolumn{2}{|c|}{$(3)$} & \multicolumn{2}{|c|}{$(4)$} \\
\hline & Coef & t-stat & Coef & t-stat & Coef & t-stat & Coef & t-stat \\
\hline & \multicolumn{8}{|c|}{ Panel A: Macroeconomic Variables } \\
\hline Dummies & Yes & & No & & No & & No & \\
\hline GDP growth & & & -819.61 & -14.58 & -528.09 & -8.92 & -494.74 & -8.35 \\
\hline GDP vol & & & 321.66 & 2.44 & & & & \\
\hline Implied vol & & & & & 323.15 & 17.38 & 268.10 & 9.32 \\
\hline Sentiment & & & -1.11 & -16.78 & -0.62 & -9.46 & -1.04 & -7.03 \\
\hline Jump $\left(\times 10^{4}\right)$ & & & 1.71 & 6.81 & -0.29 & -1.00 & -0.44 & -1.52 \\
\hline Short rate & & & & & & & -1.39 & -0.42 \\
\hline Long rate & & & & & & & 2.13 & 0.52 \\
\hline Term spread & & & & & & & -17.96 & -3.36 \\
\hline Credit spread & & & & & & & 62.76 & 9.38 \\
\hline Stock return & & & & & & & 30.41 & 0.89 \\
\hline Inflation & & & & & & & -717.36 & -4.26 \\
\hline Constant & 138.42 & 15.35 & 237.70 & 33.43 & 143.05 & 18.06 & 168.50 & 9.12 \\
\hline $\mathrm{N}$ & 24281 & & 24281 & & 24281 & & 24281 & \\
\hline \multirow[t]{2}{*}{$\operatorname{Adj} R^{2}$} & $6.3 \%$ & & $2.7 \%$ & & $4.1 \%$ & & $5.1 \%$ & \\
\hline & \multicolumn{8}{|c|}{ Panel B: Macroeconomic Condition vs Firm Characteristics } \\
\hline Dummies & Yes & & No & & No & & Yes & \\
\hline Leverage & & & & & 142.06 & 4.09 & 149.98 & 4.49 \\
\hline IV & & & 640.65 & 16.36 & 592.13 & 17.63 & 736.36 & 15.55 \\
\hline Jump $\left(\times 10^{4}\right)$ & & & & & 0.13 & 6.15 & 0.11 & 5.47 \\
\hline Constant & 97.20 & 7.25 & -97.01 & -9.71 & -125.38 & -10.36 & -145.48 & -9.89 \\
\hline$\overline{\mathrm{N}}$ & 13551 & & 13551 & & 13551 & & 13551 & \\
\hline Adj. $R^{2}$ & $6.1 \%$ & & $40.6 \%$ & & $47.2 \%$ & & $53.7 \%$ & \\
\hline
\end{tabular}

Notes: This table demonstrates how much various macroeconomic variables explain total variation of a panel of CDS spreads. The dependent variable is the 5-year monthly average CDS spreads in basis points. The independent variables for Panel A are the four monthly macroeconomic series: real GDP growth rate, GDP growth volatility estimated as the unexpected growth rate, investor sentiment proxied by Conference Board Consumer Confidence Index, and jump risk proxied by S\&P 500 index option implied volatility slope. Short rate is three-month Treasury bill yield. Long rate is ten-year government bond yield. Term spread is the yield difference between 10-year and 2-year Treasury bonds. Credit spread is Moody's Baa-Aaa yield spread. Stock return is monthly S\&P stock return. Inflation is year-over-year CPI percentage change. Issuer-clustering, cross-correlation, and heteroskedacity are adjusted to obtain robust t-statistics. Panel B independent variables include firm leverage, implied volatility and jump risk. 


\section{Table 6}

Descriptive statistics of firm characteristics

\begin{tabular}{|c|c|c|c|c|c|c|c|}
\hline \multirow[b]{2}{*}{ Variable } & \multirow[b]{2}{*}{ Obs } & \multirow[b]{2}{*}{ Mean } & \multirow[b]{2}{*}{ Std. } & \multirow[b]{2}{*}{ Min } & \multirow[b]{2}{*}{ Max } & \multicolumn{2}{|c|}{ Correlation } \\
\hline & & & & & & $(1)$ & $(2)$ \\
\hline & \multicolumn{7}{|c|}{ Panel A: Cash Flow Data } \\
\hline CVCF (1) & 20105 & 173.70 & 1912.09 & 1.41 & 168654.60 & 1.000 & \\
\hline Firm Growth (2) & 15894 & -1.15 & 43.31 & -2507.20 & 537.68 & -0.002 & 1.000 \\
\hline \multirow[t]{2}{*}{ Cash Flow Beta } & 17600 & 82.68 & 1598.29 & -8924.99 & 54788.09 & 0.010 & -0.091 \\
\hline & \multicolumn{7}{|c|}{ Panel B: Control Variables } \\
\hline Leverage (1) & 20701 & 0.30 & 0.22 & 0.00 & 1.00 & 1.000 & \\
\hline IV $(2)$ & 20444 & 0.33 & 0.14 & 0.02 & 2.08 & 0.188 & 1.000 \\
\hline Jump $\left(\times 10^{2}\right)$ & 20444 & 0.27 & 1.02 & -24.35 & 16.54 & 0.115 & 0.014 \\
\hline
\end{tabular}

Notes: This table summarizes select characteristics of our sample firms. Panel A reports cash flow estimates. $C V C F$ is the coefficient of variation in quarterly operating cash flow, a measure of cash flow volatility, in percentage. Firm Growth is firm specific growth rate. $C F$ Beta is cash flow beta. Panel B describes the control variables for our multivariate regressions: Leverage is measured as the book value of debt over the sum of book value of debt and market value of equity, $I V$ as the option implied volatility, and Jump as the slope of option implied volatility curve. Data cover the period from July 1997 to November 2006. 


\section{Table 7}

Credit spreads and cash flow characteristics

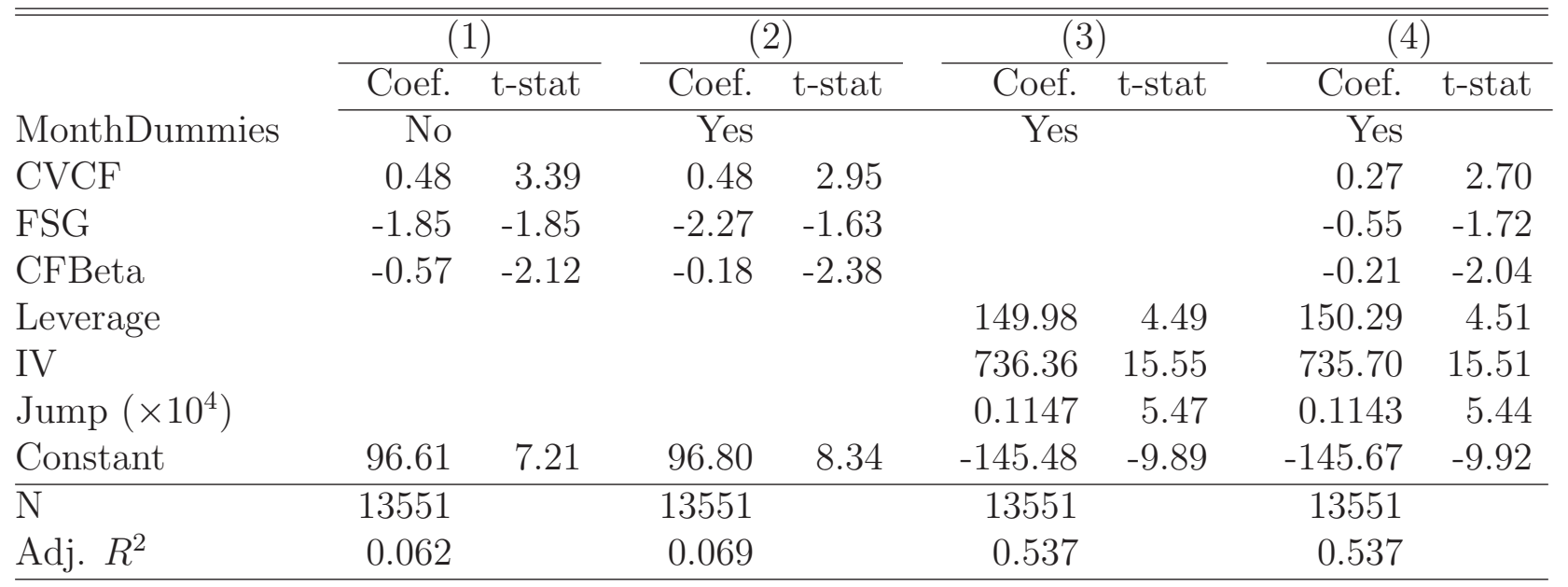

Notes: This table reports regression results for the effects of cash flow variables on credit spreads. The dependent variable is the 5-year monthly average CDS spreads in basis points. The independent variables are CVCF, FSG, CF Beta, Leverage, IV, and Jump as described in Table 6. All regressions include monthly time dummies (not shown). Issuer-clustering, cross-correlation, and heteroskedacity are adjusted to obtain robust $t$-statistics. 


\section{Table 8}

Credit spreads and cash flow beta in different economic states

\begin{tabular}{llllll}
\hline \hline GDP growth & Predicted sign & Coef. & t-stat & N & Clusters \\
\hline
\end{tabular}

Panel A: Positive Growth

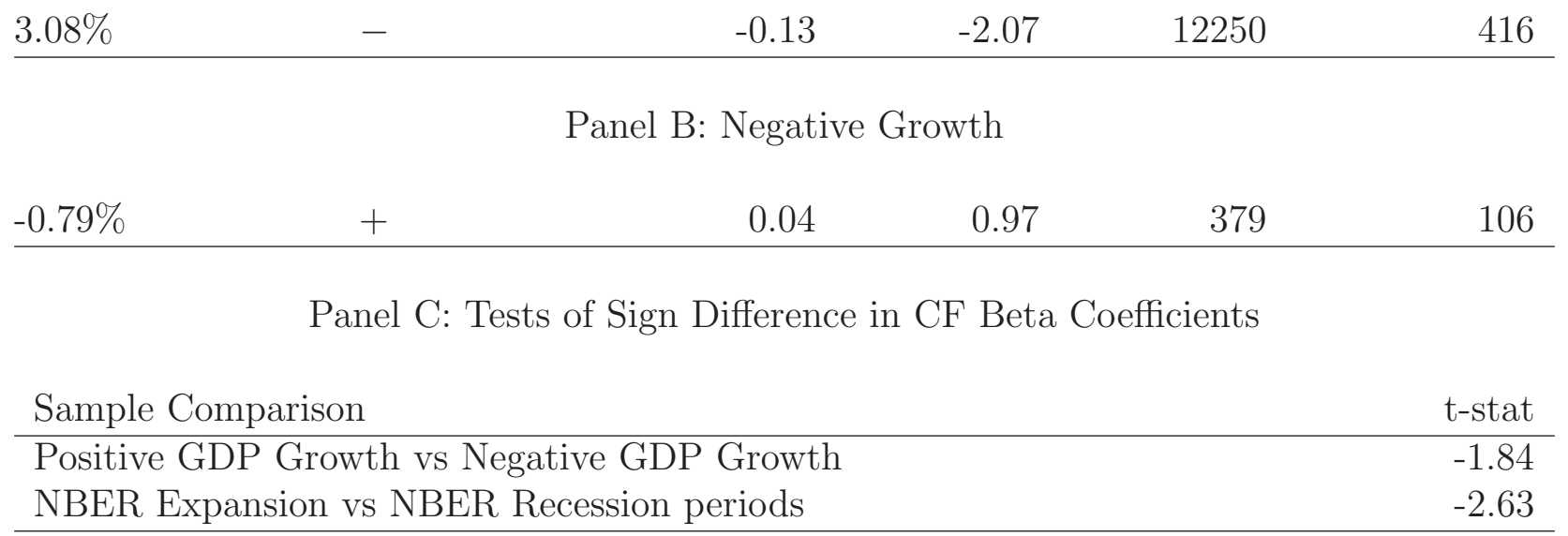

Notes: This table reports the results of the full regression in Table 7 over two subsamples: positive GDP growth periods between July 1997 and November 2006 (Panel A) and negative GDP growth periods (Panel B) covering 2000Q3, 2001Q1, and 2001Q3. The dependent variable is the 5-year monthly average CDS spreads in basis points. Only the coefficient estimate for $C F$ Beta is reported. Panel C tests the significance of the sign difference on $C F$ Beta between positive and negative GDP growth periods, as well as NBER expansion periods and one recession period (March 2001 - November 2001). 